\title{
Role and potential of decision support systems in forestry
}

\author{
Rajesh Kumar Mishra $^{1 *}$, Sharad Tiwari ${ }^{2}$ and Rekha Agarwal ${ }^{3}$ \\ ${ }^{1}$ Tropical Forest Research Institute, P.O. RFRC, Mandla Road, Jabalpur, Madhya Pradesh, India \\ ${ }^{2}$ Institute of Forest Productivity, Ranchi, Jharkhand, India \\ ${ }^{3}$ Govt. Science College, Jabalpur, Madhya Pradesh, India \\ *Corresponding Author: rajeshkmishra20@gmail.com
}

\begin{abstract}
Decision Support Systems (DSS) are essential tools for forest management practitioners to help take account of the many environmental, economic, administrative, legal and social aspects in forest management. This paper is concerned with the technique to develop DSS for forest management system to evaluate models and methods considering all the important factors to categorize the problem. The problem is based on temporal and spatial parameters, number of objectives, decision makers and goods and services. Some of these problem dimensions are inter-related, and we also found a significant relationship between various methods and problem dimensions, all of which have been analysed using contingency tables. The results showed that $63 \%$ of forest DSS use simulation modeling methods and these are particularly related to the spatial context and spatial scale and the number of people involved in taking a decision. The analysis showed how closely Multiple Criteria Decision Making is linked to problem types involving the consideration of the number of objectives, also with the goods and services. On the other hand, there was no significant relationship between optimization and statistical methods and problem dimensions, although they have been applied to approximately $60 \%$ and $16 \%$ of problems solved by DSS for forest management, respectively. Metaheuristics and spatial statistical methods are promising new approaches to deal with certain problem formulations and data sources. Nine out of ten DSS used an associated information system, but the availability and quality of data continue to be an important constraining issue, and one that could cause considerable difficulty in implementing DSS in practice. Very often DSS is used largely based to study market economy. The results suggest a strong need to improve the capabilities of DSS in this regard, developing and applying MCDM models and incorporating them in the design of DSS for forest management in coming years.
\end{abstract}

Keywords: Forest Management, Group Decision Making, Optimization, Simulation.

\section{INTRODUCTION}

Decision support systems (DSSs) are specific class of interactive computer-based information systems, which present decision alternatives (Harstela, 1997). In clear terms, they are an application primarily used to consolidate, summarize, or transform transaction data to support analytical reporting and trend analysis. Database, simulation and decision modeling and user interface are components of DSS that helps in evaluating the economic and environmental effects of different parameters. Thus, they assist the users to simulate, evaluate, and/or optimize alternatives. With DSS, a decision-maker can better understand and learn a decision-making process, and thus make better and perhaps faster decisions (Scott-Morton, 1971; Keen, 1981; Turban, 1988; Silver, 1991). However, in the recent DSS research, criticism has been directed toward the lack of interaction between the cognitive and psychological aspects of human problem solving and decision support (Carlsson, 1991; Vanharanta et al., 1997). To analyze complex problem the above decision support system were usedthat do not follow any specific commands (Manheim, 1989; Carlsson \& Walden, 1995).

Decision support systems have immense potential in the field of forestry research extension. A good decision support system provides consequences of different decision alternatives by accessing the entire current information base on the subject. Thus, they help the user to have a comparative assessment of all the available options. This quality of decision support systems makes them an efficient medium for dissemination and utilization of technological innovations. In the present paper the role and potential of decision support systems have been discussed in relation to forestry extension services.

\section{Genesis of DSS}

Decision Support Systems changed (and got better) early in the time in history of distributed figuring out/calculating. The history of such systems begins in about 1965 when the development of the IBM System 360 and other more powerful mainframe systems made it more practical and cost-effective to develop Management Information Systems (MIS) in large companies (Davis, 1974). Scott Morton (1967) described how computers and analytical models 
could help managers make a key decisionIn the decade of 1960's management decision system has been evolved. The publications on management decision system, strategic planning systems and decision support systems has been started around 1970 in business journals (Sprague \& Watson, 1979). In 1970's criteria to design model to support management decision making system was used. These criteria were robustness, ease of control, simplicity and completeness of relevant detail. All these criteria are still used in modern decision support system. In 1971, Michael S. Scott Morton has ground-breaking book Management Decision Systems: Computer-Based Support for Decision Making was published. In the later part of 1970's decade interactive information system was used for semi structured problems. They were called Decision Support System. It was recognized that DSS could be designed to support decision-makers at any level in an organization. Financial management and strategic decision making may utilize the DSS. DSS may be utilized in Geo data Analysis and Display System (Grace, 1976) as well as structured multidimensional data and unstructured documents (Swanson \& Culnan, 1978). A variety of models was used in DSS including optimization and simulation. In addition, statistical packages were recognized as tools for building DSS. According to Gray (1981), Huber (1982) and Turoff \& Hiltz (1982) a new category of software was developed to support decision support system by the researchers. Examples of early Group DSS were Mindsight from Execucom Systems, GroupSystems developed at the University of Arizona and the SAMM system developed by University of Minnesota researchers.

In the 1990's there was a switchover from mainframe based to client/server based DSS system. Some desktop OLAP tools were introduced during this time. Object oriented technology to be used for making reusable decision support capabilities were start recommending by vendors during 1992-93. In this decade many companies upgraded their network infrastructure. DBMS vendors started implementing OLAP capabilities into their database. In mid 90's web based DSS systems came in to existance (Power, 2000; Bhargava \& Power, 2001).

\section{Pre-requisite for DSS in forestry extension}

DSS is of two types, model driven and data driven. For limited data set model driven DSS is applied. A user can communicate with this decision support system by specifying a number of "what-if" scenarios. For example, what will be economics of growing a particular tree species in particular site condition. In data driven DSS system large amount of data is analyzed collected over a long period of time known as mining. Data mining searches for significant patterns, with which decisions can be made. Data driven DSS systems uses statistical analysis and rely on artificial intelligence like neural networks and intelligent agents.

With help of special category of DSS systems decision makers can work together without being at same place and time and reach a consensus. In geographic information system, information is extracted from digitalized maps. For example, by looking at a location of a forestry species over a digitized map, one can easily establish a pattern of geographic distribution of the species.

Whatever, be the type of decision support system, to be effective in forestry research extension it must possess some important characteristics. As an audience, which is less academic in nature, will utilize extension-oriented decision support systems simplicity and user-friendliness holds the key to success. An efficient decision support system for forestry extension must be uncomplicated in operation and unambiguous in offering solutions. It should be necessarily interactive so that the user can optimally utilize the information in different perceived situations. Sincethe extension is aimed at community benefit any decision support system devised for the purpose must be cost-effective. Research institutions and the governmental agencies should take adequate measures to cut down the cost of the system to enhance their use by intended beneficiaries.

Effective dissemination rests upon how much the disseminator knows about the intended recipient audience. Individuals and groups are active participants in the construction and disseminating of knowledge. It is important that the technological innovation or research results to be disseminated must address the concerns of a potential user. Thus, a simple user analysis should be conducted for an extension-oriented decision support system. Potential users are integral part of any system development process. They can suggest their requirements and expectations for a decision support system.

\section{DSS in forestry}

A large number of Decision Support Systems are available to assist the users to come to a logical scientific conclusion on a variety of situations in forestry. Most of these are commercial, while some of these are of research projects carried out by universities, research organisations and forest authorities. Some of the important Decision Support Systems have been enlisted below:

\section{- Woodplan Software for Forestry and Estate Management}

This package provides full suite of forest management software. 


\section{- Remsoft - Woodstock - Forest Modeling System}

This Forest modeling system can be used in harvest scheduling and wood supply analysis, wildlife management and simulation of forest ecosystems.

- Remsoft - Stanley - Spatial harvesting block scheduling

This package automates the process of developing a spatial harvest plan.

- Assisi ForestTM 98 / Assisi ForestTM 2000

This forestry simulation program can be used to design harvesting plans.

- Assisi InventoryTM 2000

This is a Forest inventory package which is used to store raw inventory data and compile volume and value estimates.

\section{- NED Software products}

NED is a collection of software products being developed by the USDA Forest Service. The software is intended to aid resource managers, develop goals, assess current and future conditions and produce sustainable management plans for forest properties.

\section{- FORVAL - Timberland Investment Appraisal}

This is a Forestry evaluation software.

- SVS - Stand Visualisation System

This Software generates graphics to depict various stand conditions.

- Softree - Natural Resource Software - Terrain Tools

This is a mapping package.

\section{- Fors/map for Windows - Desktop Mapping System}

This provides mapping facility customized with enhancements for forestry and natural resources.

\section{- Forestry Compendium}

It is a silvicultural reference tool to assist in selection of species for trials in plantation, agro-forestry and natural forest systems.

\section{- Woods of the World CD}

This is a Multimedia database of detailed information on up to 910 wood species and products, covering $95 \%$ of the wood types in trade. Educational/extension use.

\section{- Spectrum}

It is an Analytical Tool to Support Ecosystem Management.

\section{- SILVAH}

This package assists making silvicultural decisions in hardwood stands. SILVAH also contains a forest stand growth simulator, provides the ability to test alternative cuts, enables development of a forest-wide inventory database, and facilitates other forest management planning functions.

\section{- Smart Forest}

It is an interactive forest visualizer, which enables users to develop models of forests on a large or small scale, based on data from ground surveys, sample plot data, aerial photo surveys for forest cover and digital terrain data.

\section{DSS for suitability of tree species in central India}

The world's rapidly growing population requires most countries to make the best possible use of their land resources for agriculture, horticulture, forestry and conservation. For land use planning, it is necessary to predict the conditions for growth in different area. GIS and modeling can be used for this but decision makers and researchers do not have much access to these technologies. Climate has an important influence on tree growth. It is particularly useful as a means to predict where a particular tree will grow, as mean climatic conditions can now be reliably estimated for most locations around the world. Being able to identify where particular plants will grow is useful, but many people need to know how well they will grow on particular sites. Generally, they do not require highly precise predictions of yield, but they do need to know whether the growth will be good, fair or poor. We are currently engaged in the development of a system to predict the suitability of important forestry species in different climatic and edaphic conditions in central India. This user-friendly and interactive programme has been envisaged to help the tree planters to identify the most suitable forestry species to the prevailing growing conditions. The system will require data on simple ranges of climatic 
and edaphic conditions and the program will show which areas, if any, satisfy those sets of conditions. The system will be designed to provide information based on plant name, climatic and edaphic data and location wise. The logical flowchart of the system is shown in figure 1 .

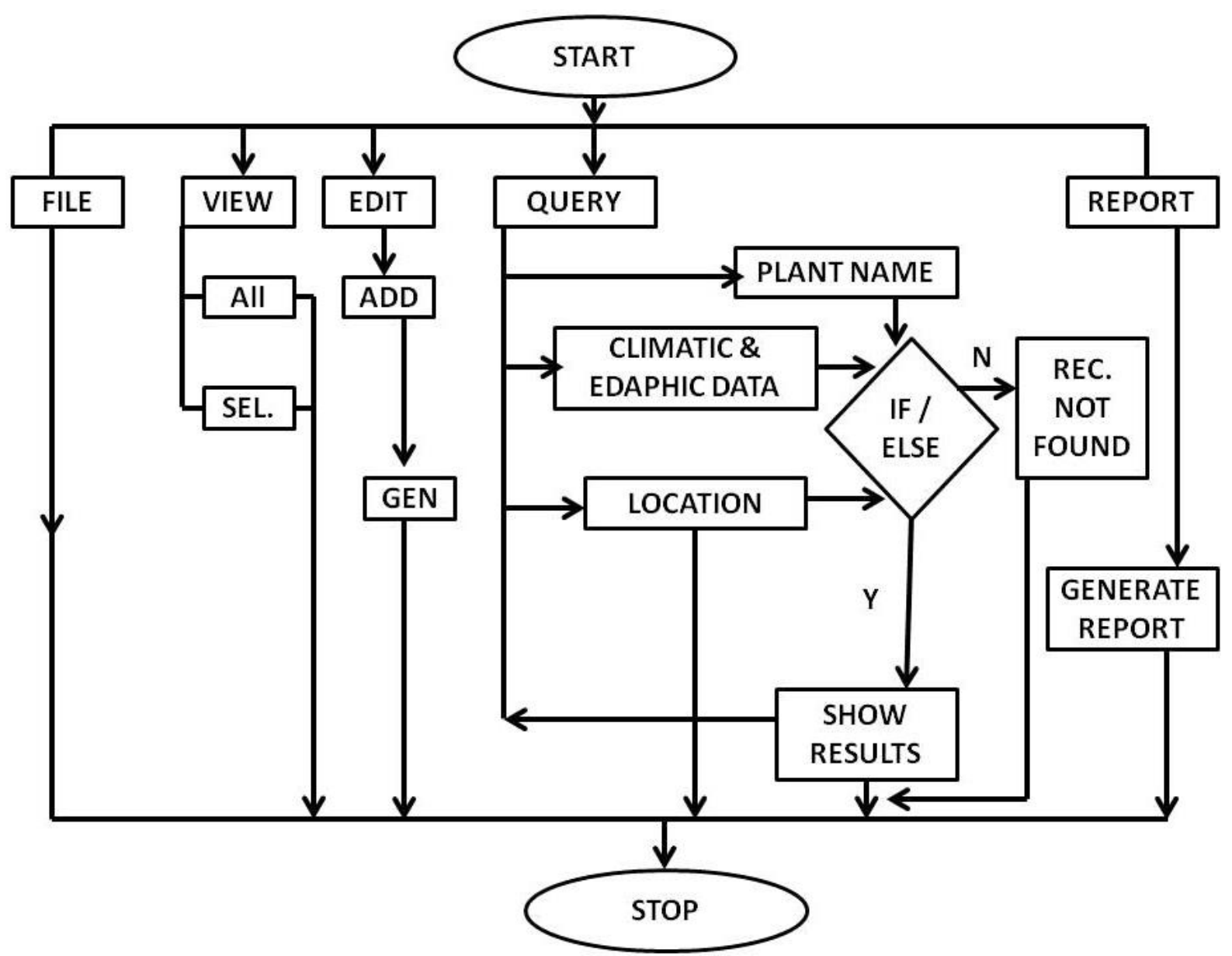

Figure 1. Flow chart of the system for predicting suitability of tree species.

\section{CONCLUSIONS}

We have discussed the concept, characteristics and evolution of decision support system. It is evident that these systems being interactive, fast and cost-effective are of great help in dissemination and effective utilization of forestry research. However, simplicity and unamibiguity should form the most important considerations in the development of a decision support system for forestry extension. Thus, more decision support systems like a prediction of the suitability of tree species need to be evolved.

\section{Future scope}

The decision support systems make use of variety of technology and new technologies playing important role in decision-making. One such technique is Geographic Information Systems (GIS). Recently the need of site based information along with geographical details has been arise. This gives a clear information about the object. Many areas of DSS system are concerned with geographic details. GIS based DSS can make use of spatial data processing. In future SDSS will be important and will be used by the users without any special skillin GIS application. SDSS gives geographic analysis without requiring in-depth commands to operate. In future SDSS users will be able to control the variables important in decision making while other processing is performed without user interaction. With the development of such systems, new classes of the decision and a new class of users will be supported effectively.

\section{ACKNOWLEDGEMENTS}

Authors are grateful to Dr. G. Rajeshwar Rao, Director and Shri C. Behera, Group Coordinator (Research), Tropical Forest Research Institute, Jabalpur- 482021 (M.P.), for providing necessary research facilities to carry out this work.

\section{REFERENCES}

Bhargava H. \& Power D.J. (2001). Decision Support Systems and Web Technologies: A Status Report. In: Proceedings of the 2001 Americas Conference on Information Systems. August 3-5, 2001, Boston. 
Carlsson C. \& Walden P. (1995). More effective strategic management with hyperknowledge: The Woodstrat case. Institute for Advanced Management Systems Research. Research Report 3, 26 p.

Carlsson C. (1991). New instruments for management research. Human Systems Management, 10: 203-220.

Davis G. (1974). Management Information Systems: Conceptual Foundations. In: Structure and Dvelopment. McGraw-Hill, New York.

Grace B.F. (1976). Training Users of a Decision Support System. IBM Research Report RJ 1790, IBM Thomas J. Watson Research Laboratory.

Gray P. (1981). The SMU decision room project. In: Transactions of the $I^{\text {st }}$ International Conference on Decision Support Systems, Atlanta. pp. 122-129.

Harstela P. (1997). Decision support systems in wood procurement. A review. Silva Fennica, 31: 215-223.

Huber G.P. (1982). Group decision support systems as aids in the use of structured group management techniques. In: Transactions of the $2^{\text {nd }}$ International Conference on Decision Support Systems. pp. 96-103.

Keen P.G. (1981). Information systems and organizational change. Communications of the ACM, 24: 24-33.

Manheim M.L. (1989). Issues in design of a symbiotic DDS. In: Proceedings of the $22^{\text {nd }}$ Annual Hawaii International Conference on System Sciences, Vol. VII., IEEE Computer Society Press, pp. 14-23.

Power D.J. (2000). Web-Based and Model-Driven Decision Support Systems: Concepts and Issues. In: Proceedings of the 2000 Americas Conference on Information Systems, Long Beach, California, August 10 - 13, 2000.

Scott-Morton M.S. (1967). Computer-Driven Visual Display Devices - Their Impact on the Management Decision-Making Process, (Doctoral Dissertation). Harvard Business School.

Scott-Morton M.S. (1971). Management decision systems: computer-based support for decision making. Harvard University, Boston, $216 \mathrm{p}$.

Silver M.S. (1991). Systems that support decision makers. John Wiley \& Sons, Chichester, 254 p.

Sprague Jr. R.H. \& Watson H. J. (1979). Bit by Bit: Toward Decision Support Systems. California Management Review, 22 : 60-68.

Swanson E.B. \& Culnan M.J. (1978). Document-Based Systems for Management Planning and Control: A Classification, Survey and Assessment. MIS Quarterly, 2: 31-46.

Turban E. (1988). Decision Support and Expert Systems - Managerial Perspectives. Macmillan Publishing Company, New York, $697 \mathrm{p}$.

Turoff M. \& Hiltz S.R. (1982). Computer support for group versus individual decisions. IEEE Trans Communications, 1: 8290.

Vanharanta H., Pihlanto P. \& Chang A.M. (1997). Decision support for strategic management in a hyper-knowledge environment and the holistic concept of man. In: Proceedings of the $30^{\text {th }}$ Annual Hawaii International Conference on System Sciences, Vol. V, IEEE Computer Society Press. pp. 243-258. 